\title{
Tecnologias da informação e comunicação na educação: conceitos e definições
}

\author{
Luciana Maura Aquaroni Geraldi ${ }^{1}$ \\ José Luís Bizelli²
}

\begin{abstract}
Resumo: As tecnologias da informação e comunicação (TIC) trazem novas formas e métodos de produção do conhecimento no ambiente escolar. Inovações tecnológicas permitem melhorar a relação Escola/professor; professor/estudante e estudante/estudante. Para tanto, faz-se necessário entender a utilização das ferramentas informatizadas e seus resultados. $\mathrm{O}$ texto aqui apresentado faz uma revisão da bibliografia pertinente ao tema analisando formas de trabalhar e inserir TIC no cenário da sala de aula. A perspectiva da abordagem proposta indica a importância de investimentos no acesso e letramento para o uso de inovações, começando pela formação de educadores aptos a rever seus métodos e práticas de ensino.
\end{abstract}

Palavras-chave: educação; inovação; formação de professores; TIC.

Abstract: Information and communication technologies (ICT) bring new ways and knowledge of production methods in the school environment. Technological innovations allow to improve the relationship School / Teacher; teacher / student and student / student. Therefore, it is necessary to understand the use of digital tools and their results. The text presented here analyzes the relevant literature to the theme of ways of working and put ICT in the classroom setting. The prospect of the proposed approach shows the importance of investments in access and literacy for the use of innovations, starting with the formation of educators able to review their teaching methods and practices.

Keywords: education; innovation; teacher education; ICT.

\section{Introdução}

As inovações tecnológicas produzidas pelas Tecnologias de Informação e Comunicação (TIC) vêm provocando profundas mudanças na sociedade atual inclusive no como fazer Educação no mundo das telecomunicações e da informática (BIZELLI, 2013; LÉVY, 1998). Muito antes do surgimento do computador - que hoje integra

\footnotetext{
${ }^{1}$ Doutora em Educação Escolar pela Faculdade de Ciências e Letras da Unesp de Araraquara (FCLAr) e mestre em Engenharia (USP). Docente no ITES - Instituto Taquaritinguense de Ensino Superior e da Faculdade São Luís de Jaboticabal, onde coordena os cursos de Pós-Graduação em Informática aplicada à Educação Matemática, em Análise de Segurança Digital e em Gestão de Projetos. Email: laquaroni@yahoo.com.br

${ }^{2}$ Pós-Doutor em Educação na Universidad de Alcalá de Henares, Espanha. Professor Adjunto da FCL-Ar vinculado aos Programas de Pós-Graduação em Educação Escolar (FCL-Ar) e em Mídia e Tecnologia (FAAC-Bauru). Email: bizelli@ @fclar.unesp.br
} 
praticamente quase todas as formas estruturais da informação -, em 1945, Vannevar Bush idealizou, com admirável exatidão, aplicações como hipertexto, multimídia, armazenamento ótico, interfaces gráficas, sistemas de informação, bibliotecas virtuais, publicações eletrônicas e também aprendizagem auxiliada pelo computador (BULKELEY, 1997).

Previsões como essas mostram que a expectativa de se utilizar inovações tecnológicas para promover diversos aspectos educacionais já existiam antes mesmo do desenvolvimento dos recursos técnicos que demonstraram sua viabilidade.

Para Thompson (1998), as TIC são potencializadoras da mídia que está associada à visão de mundo dos indivíduos contemporâneoas, redefinindo valores $\mathrm{e}$ comportamentos sociais, consolidando o domínio da comunicação e do entretenimento no jogo institucional de cada sociedade concreta.

É fundamental entender que a relação entre tecnologia e educação se concretiza em princípios e processos de ação educativa, gerando produtos educativos, todos resultantes da aplicação do conhecimento científico e organizado à solução ou encaminhamento de problemas e processos educacionais (NETO, 1982, p. 2). No sentido amplo, toda técnica ou recurso utilizado para realizar alguma operação ou processamento sobre algum tipo de informação, configura uma tecnologia de informação.

O termo informação atua como elemento importante em todos os setores da atividade humana, constituindo-se como dados organizados e comunicados. Considerase como elemento básico na conquista de uma melhoria na qualidade de vida, e, para Castells (1999), a informação é fundamental para conduzir a criação de conhecimentos e atender às necessidades dos indivíduos e das organizações; portanto, a necessidade do acesso à informação deve significar responsabilidade social e política.

\section{Tecnologias para a Educação}

Revendo a história da inserção das novas tecnologias da informação e da comunicação na educação pública do Brasil, pode-se notar que esta já passou por várias fases. Segundo Almeida (2001), por volta dos anos 90 (noventa), a primeira versão do Programa Nacional de Informática em Educação visava à preparação de professores para o uso da informática com seus estudantes e a criação de centros de informática educativa, localizados nas Secretarias Estaduais de Educação, que eram responsáveis pela preparação de professores e pelo atendimento aos educandos de escolas públicas no que diz respeito ao uso do computador. 
Esse programa apenas formou professores em pequena escala e não conseguiu chegar à sala de aula. Já, um programa mais recente do MEC, ProInfo, que se desenvolve por meio de parceria com as Secretarias Estaduais de Educação, começa a concretizar o uso da TIC, ao inserir o computador na escola para ser incorporado à prática pedagógica de diferentes áreas de conhecimento, favorecendo a aprendizagem do aluno. Esse programa prioriza a formação de professores e educadores em um processo que integra o domínio da tecnologia, teorias educacionais e prática pedagógica com o uso dessa tecnologia (ALMEIDA, 2001).

Carneiro (2002, p. 50-51) destaca que,

[..] dentre as razões oficiais para a implantação dos computadores nas escolas, a aproximação da escola dos avanços da sociedade no que se refere ao armazenamento, à transformação, à produção e à transmissão de informações, favorecendo a diminuição da lacuna existente entre o mundo da escola e a vida do aluno - o que diminuiria também "[...] as diferenças de oportunidade entre a escola pública e a particular, cada vez mais informatizada." Por outro lado, ela ressalta que "[...] pouco se discute quais os modos de informatização que estão sendo trabalhados e com que finalidade."

Pode-se notar que algumas ações foram implantadas pelo Governo Federal, a partir do Programa Sociedade da Informação, como mostra a Figura 2:

Figura 1- Projetos do Governo Federal para uso das TIC

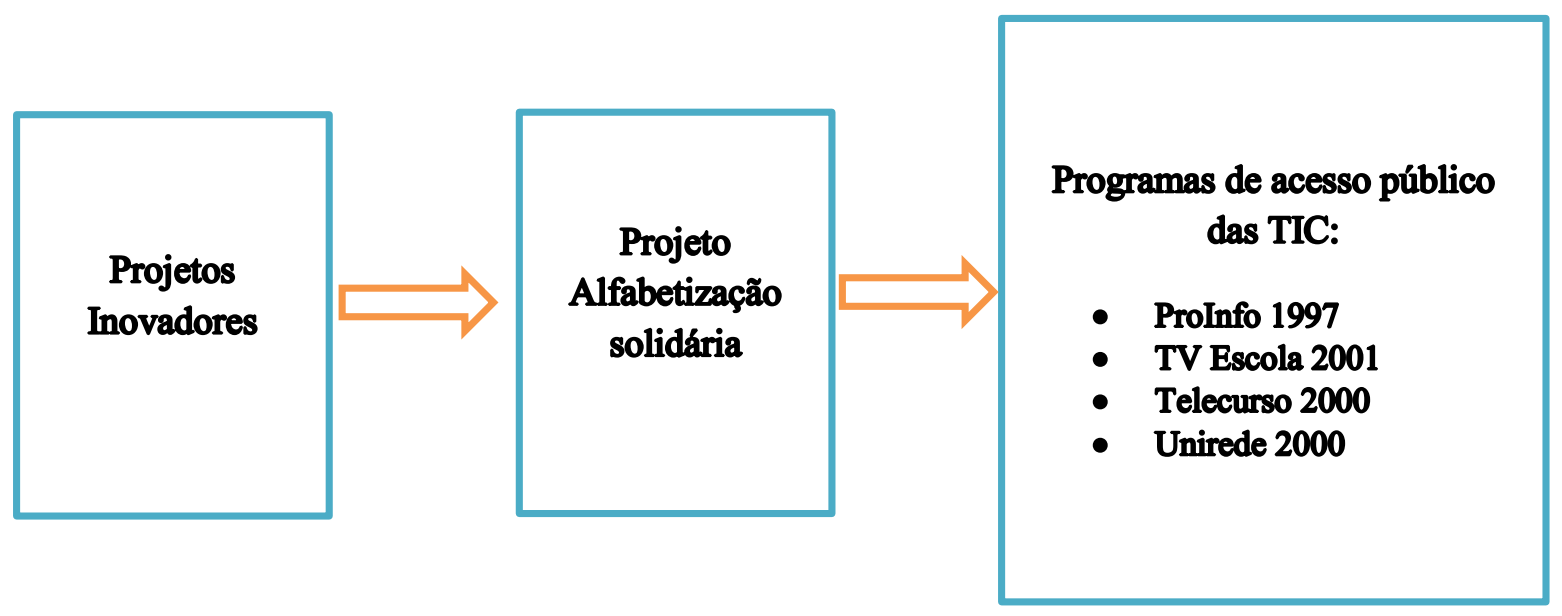

Fonte: Adaptado de Silva (2007). 
Em decorrência da LDB no 9394 de 1996, as Diretrizes Curriculares Nacionais (DCN) da Educação Básica do ano de 2013 também lançam os princípios da organização curricular do Ensino Fundamental e do Ensino Médio, determinando que

A base nacional comum dos currículos do Ensino Médio será
organizada em áreas de conhecimento, a saber: linguagens,
códigos e suas tecnologias; ciências da natureza, matemática e
suas tecnologias; ciências humanas e suas tecnologias (art. 10 da
Resolução CNE/CEB n. 03/98).

É inevitável a associação do termo tecnologia de informação com informática, rede de computadores, Internet, multimídia, banco de dados e demais recursos oferecidos por essa ferramenta. Todas as outras tecnologias (telefone, rádio, TV, vídeo e áudio), que antes eram utilizadas em separado, hoje foram integradas por meio do computador e seus periféricos, como câmeras de vídeo, impressoras, conexão à Internet, leitores e gravadores de discos óticos, sistemas de áudio, estações de rádio e TV acessíveis via Internet (VEEM; VRAKKING, 2009).

Nesse contexto, pode-se visualizar que os usuários vivem na sociedade da informação e apoiam-se no uso intensivo das novas tecnologias. Elas retratam uma organização social moderna, na qual as redes de comunicação e os recursos tecnológicos são altamente desenvolvidos, o acesso equitativo e onipresente às informações, o conteúdo apropriado em formatos acessíveis e a comunicação eficiente devem possibilitar que todas as pessoas alcancem seu potencial pleno. O controle e o domínio dessas tecnologias têm decidido a sorte das sociedades (CHAHIN et al., 2004).

O desenvolvimento da sociedade depende, hoje, da capacidade de gerar, transmitir, processar, armazenar e recuperar informações de forma eficiente. Por isso, a escola precisa ter oportunidades de acesso a esses instrumentos e adquirir capacidade para produzir e desenvolver conhecimentos utilizando a TIC. Isso requer a reforma e a ampliação do sistema de produção e difusão do conhecimento, possibilitando o acesso à tecnologia. Entretanto, o simples acesso à tecnologia, em si, não é o aspecto mais importante, mas, sim, a criação de novos ambientes de aprendizagem e de novas dinâmicas sociais a partir do uso dessas novas ferramentas (MORAES,1997).

Parece consenso, mas para Castells (1999), Johnson (2001), Brunner (2005) e Kenski (2007), vive-se na sociedade da informação, em uma sociedade tecnológica (VIEIRA PINTO, 2005) ou sociedade midiática (PIMENTA, 1999), em que se constata o uso cada vez mais frequente das tecnologias digitais em práticas cotidianas, que 
resultam em mudanças ou incorporações de novas práticas sociais (BORGES, 2007). O fato é que as tecnologias digitais assumiram o papel de "tecnologias", característica marcante das sociedades atuais, conforme se apresenta na Figura 3:

\section{Figura 2- Características da sociedade da informação}

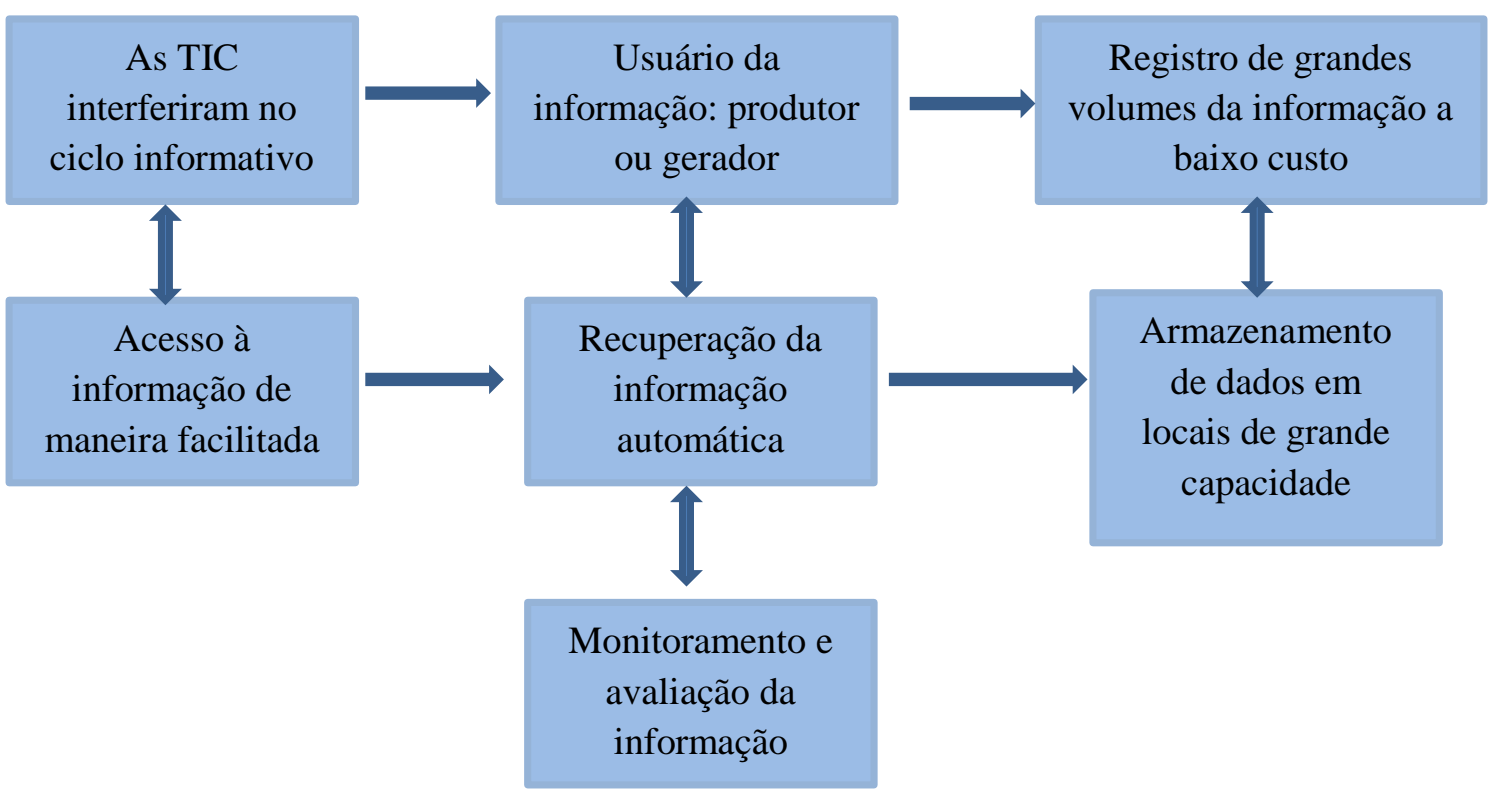

\section{Fonte: Adaptado de Castells (1999)}

Para Ribas (2007, p.50):

A tecnologia tem transformado os processos e as práticas tradicionais da educação e da socialização do conhecimento mediante inovações que têm modificado as formas de produção, distribuição, apropriação, representação, significação e interpretação da informação e do conhecimento.

A introdução das tecnologias da informação e da comunicação no processo educacional tem a finalidade de intensificar a melhoria dos recursos midiáticos utilizados em sala de aula pelos professores que atuam em uma instituição de ensino, seja ela particular ou pública. A tecnologia vem modificando os conceitos de toda a sociedade ao longo de sua evolução pela história. No campo educacional, o resultado não seria diferente, ela torna-se mais uma ferramenta no processo de ensino-aprendizagem.

É neste sentido que Sancho e Hernández (2006, p. 20 e 21) argumentam: 
[...] tende-se a se pensar que as tecnologias digitais de informação e comunicação fazem surgir novos paradigmas ou perspectivas educacionais e ajuda a explicar por que praticamente todas as perspectivas sobre o ensino e a aprendizagem podem argumentar que encontraram no computador um aliado de valor inestimável.

A tecnologia deve ser utilizada como um catalisador de uma mudança do paradigma educacional (VALENTE, 1993). Um paradigma que promove a aprendizagem ao invés do ensino, que coloca o controle do processo de aprendizagem nas mãos do aprendiz e que auxilia o professor a entender que a educação não é somente a transferência de conhecimento, mas um processo de construção do conhecimento pelo aluno, como produto do seu próprio engajamento intelectual ou do aluno como um todo (NEITZEL, 2001).

A presença de tecnologias de informação e de comunicação nos meios educacionais é cada vez mais visível. As grandes mudanças que ocorreram na educação, e, mais precisamente, na teoria pedagógica estão de certo modo ligadas às transformações que se deram nos meios de comunicação: ora da educação realizada por meio da oralidade e da imitação ao ensino por meio da linguagem escrita, tendo como seu principal suporte o livro impresso, ora dos recursos computacionais hoje disponíveis (QUARTIERO, 1999).

Computadores (hardware) cada vez mais poderosos permitem o surgimento de ferramentas (software) extremamente sofisticadas de apoio ao ensino, como sistemas de autorias e sistemas de hipertexto, utilizando multimídia e inteligência artificial. Isso caracteriza os avanços tecnológicos que foram realizados na área da informática e da comunicação.

De acordo com Castro (2000), as tecnologias da informação são recursos que auxiliam o professor no processo de ensino-aprendizagem, transmitindo o conhecimento de uma forma criativa, dinâmica e contribuindo ao direito de estudar e aprender com mais atratividade e interação.

Para Simões (2002, p.33), a tecnologia da informação e da comunicação na educação teve seu início,

[...] por volta dos anos 50 e 60 do século XX, a Tecnologia Educacional era vista como o estudo dos meios geradores de aprendizagens. No Brasil só a partir dos anos 60 iniciou-se uma 
discussão mais sistematizada sobre o assunto no interior das instituições educacionais, e sua utilização, naquele momento, era fundada no tecnicismo.

A inserção da tecnologia da informação e da comunicação na sociedade trouxe transformações diversas ao ser humano, pois, por meio dela, é possível gerir conhecimento em qualquer lugar do mundo, permitindo que a troca de informações entre as pessoas seja possível e facilitada, independentemente do formato ou da distância envolvida.

Segundo Álvaro Vieira Pinto (2005, p.520),

$\mathrm{Na}$ etapa social em que agora se encontram as sociedades desenvolvidas, o intercâmbio acelera-se incessantemente. Inventam-se continuamente novas técnicas, porque a realidade se modificou, e ao mesmo tempo a realidade se modifica mais intensa e profundamente porque foram criadas técnicas novas. [...] A tecnologia progride sem cessar porque faz progredir a razão subjetiva que apreende os efeitos dela sobre a produção materiais de bens e as influências exercidas nas relações sociais entre os homens durante o trabalho.

Na concepção de Alava (2002, p.13-21), um espaço tecnológico não pode ser reduzido a

[...] transmissão passiva de saberes. A emergência de novos dispositivos de formação abertos nas instituições de ensino, no campo da formação profissional, tende a colocar de novo na ordem do dia ideias antigas, mas sempre atuais, de trabalho colaborativo, de autonomia dos aprendizes e métodos ativos. Assim, "o ciberespaço é concebido e estruturado de modo a ser, antes de tudo, um espaço social de comunicação e de trabalho em grupo".

Os recursos mais utilizados para o processo ensino-aprendizagem são, conforme ilustra a Figura 4:

Figura 3- Características da sociedade da informação 

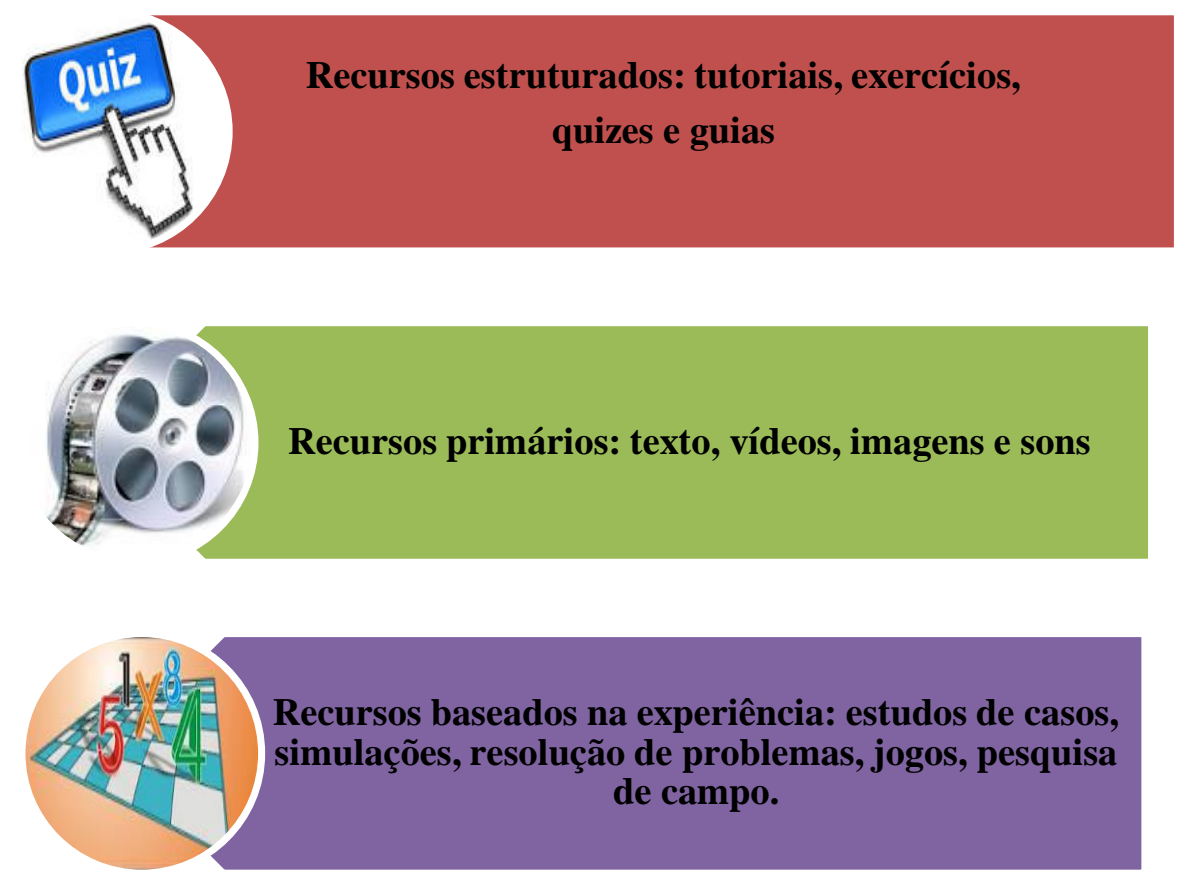

\section{Fonte: Adaptado de Maier e Warren (2000)}

Os acessos aos recursos de aprendizado nunca foram tão fáceis como via Internet. Em poucos anos, computadores e telecomunicações de alto desempenho serão utilizados como material didático. Do mesmo modo, comunidades virtuais e ambientes artificiais compartilhados farão parte da rotina do dia a dia, como o telefone, a televisão, o rádio e os jornais são hoje (CRUZ; MORAES, 2002).

É inegável que as transformações em relação à cultura tecnológica, que diz respeito às novas metodologias de ensino e aprendizagem associadas a ferramentas computacionais, tragam mudanças de paradigmas fatuais às premissas educacionais. Revela-se a importância do que coloca Bizelli (2013), ao analisar a sociedade da informação e preconizar que três princípios devem orientar as políticas públicas em todas as sociedades concretas: universalização da Educação; universalização do acesso às TIC e construção da participação na gestão. Somente o atendimento aos pré-requesitos esboçados pode permitir o acesso e a apropriação sobre os meios que permitam o exercício da liberdade na busca pelos interesses individuais e acima deles aos interesses cidadãos.

Para a construção de uma Educação assim definida, aqueles docentes que nunca deixaram de lado a lousa e o giz, têm que assumir novas concepções de ensino caracterizadas por meio de projeções inovadoras que não fazem parte de seu tempo. Eles 
consideram, em sua maioria, que não vale a pena aprender o novo e que isso deve ser algo a ser praticado pela nova geração, os voltados à era da informação.

Os "professores da nova geração" - rótulo dado pelos próprios companheiros de categoria - também aprenderam o ofício da docência por meio de ferramentas consideradas obsoletas, porém, aprendendo com as inovações, são detentores de conhecimentos que, em sua amplitude, ampliam redes de relações cujo principal elemento é a troca de informação, seja ela falada ou escrita, esteja inserida em multiplataformas tecnológica.

\section{O professor e as TIC}

Santos (SANTOS et al., 2010) afirma que o desenvolvimento das novas tecnologias na sala de aula não diminui o papel dos educadores, pelo contrário, ele deixa de ser o transmissor do saber, tornando-se um elemento do conjunto, organizando o saber coletivo.

Para Terry Evans (2002, p.3),

Uma peça de giz e quadro-negro ou mesmo um galho e um chão de areia são ferramentas nas mãos de um "mestre". Tais educadores podem ser professores da escola primária, instrutores militares, idosos de uma tribo ou educadores de outdoors usando suas ferramentas para ensinar um aspecto de sua cultura aos aprendizes. De modo similar, equipamentos de videoconferência ou computadores pessoais podem ser usados como ferramentas educacionais por educadores que saibam (a tecnologia de) como usá-las para propósitos pedagógicos. Ferramentas e tecnologias são tão fundamentais para educação que é difícil imaginá-la sem eles; especialmente os sons e símbolos como ferramentas, e a escrita e a linguagem como tecnologias.

Takahashi (2000) defende que,

[...] a educação é o elemento-chave para a construção de uma sociedade da informação e condição essencial para que pessoas e organizações estejam aptas a lidar com o novo, a criar e, assim, garantir seu espaço de liberdade e autonomia. Isto porque a educação deve permanecer ao longo da vida para que o indivíduo tenha condições de acompanhar as mutações tecnológicas (TAKAHASHI, 2000, p.45).

Hoje, a incorporação de algumas mídias como DVD, televisões e acesso à Internet em sala de aula já não gera surpresa e estranhamento aos profissionais que procuram dinamizar o ensino e não ficam totalmente presos ao livro didático. Mas, para que esses 
recursos gerem resultados positivos no ambiente da sala de aula, primeiramente, deve ser feito um planejamento referente ao conteúdo programático ministrado nas aulas, que contemple a inclusão dos novos recursos tecnológicos. Com isso, o aproveitamento será notório por parte dos professores que esperam o êxito como resultado, bem como dos estudantes, que terão o retorno dessas respostas. Ainda nesse processo de planejamento da inserção das TIC na sala de aula, caso não aconteça como o esperado, o professor deve repensar suas estratégias, identificar os pontos críticos e observar as reações que ocorreram no entorno daquele cenário em relação às mudanças propostas.

Souza (2007, p.3) refere-se ao uso da tecnologia nas escolas como:

O uso da tecnologia nas escolas requer a formação, o envolvimento e o compromisso de todos os profissionais no processo educacional (educadores, diretores, supervisores, coordenadores pedagógicos), no sentido de repensar o processo de informações para transmitir conhecimentos e aprendizagem para a sociedade.

Por isso, é dever do professor assumir o papel de investidor da sua própria formação, enfrentando novos desafios, buscando refletir sobre sua prática pedagógica, no sentido de superar os obstáculos e aperfeiçoar o processo de ensino-aprendizagem (NOGUEIRA, 2010). Confrontando algumas considerações atuais sobre o aspecto da tecnologia da informação e comunicação, autores como Pretto (1999) e Vargas (1994) afirmam, respectivamente:

Num país onde a escola ainda assume o papel de assistente social e perde de vista sua função de produzir e "reproduzir" o conhecimento, faz-se necessário resgatar sua função primordial de formar o cidadão para a sociedade atual, onde o próprio trabalho assume uma nova conceituação, como "trabalho informatizado, automatizado, escritórios virtuais em tempos, de menos deslocamentos e mais interação" (PRETTO, 1999, p. 105).

Em uma conjuntura ladeada de perspectivas positivas por parte dos docentes e discentes no uso das TIC estabelece-se uma concordância com a visão de Lévy (2000), quando comenta:

A tecnologia não é boa nem má, dependendo das situações, usos e pontos de vista, e "tampouco neutra, já que é condicionante ou restritiva, já que de um lado abre e de outro fecha o espectro de possibilidades". Não se trata de avaliar seus impactos, mas de situar possibilidades de uso, embora, "enquanto discutimos possíveis usos de uma dada tecnologia, algumas formas de usar 
já se impuseram", tal a velocidade e renovação com que se apresentam (LÉVY, 2000, p. 26).

Em relação às possibilidades de uso da tecnologia da informação e comunicação, portanto, deve-se lembrar de que alguns contextos, como sociais, culturais e financeiros, estão relacionados entre o usuário e a tecnologia, no sentido de limitar ou ampliar as relações com as TIC na escola. Sendo o professor e o aluno usuários dessas TIC, pode-se perceber que muitas escolas, em especial as escolas da rede pública, ainda não estão preparadas para incorporar diferentes formas de aprendizagem por meio dessas tecnologias, pois se faz referência, nesses casos, a educadores, educandos, coordenadores e diretores dessas escolas que podem ser considerados apenas telespectadores da tecnologia e não disseminadores de conhecimento por meio dela.

Para compreender esse contexto, Orozco (2002, p.65) afirma que:

O “tecnicismo por si só não garante uma melhor educação. [...] se a oferta educativa, ao se modernizar com a introdução das novas tecnologias, se alarga e até melhora a aprendizagem; no entanto, continua uma dúvida". Para o autor, cada meio e cada tecnologia exercem uma mediação particular nas pessoas e contextos com os quais interatuam, pressupondo transformações na organização do trabalho, nos seus componentes e, consequentemente, na instituição educativa que realiza o trabalho.

As tecnologias não substituem o professor, mas permitem que algumas das tarefas e funções dos professores possam ser modificadas (MORAN, 1998). A tarefa de passar informações pode ser deixada aos bancos de dados, livros, vídeos ou programas em CDROM, segundo Freire e Shor (1986).

Para Mitra (2012, p.3), o papel do professor com a inserção da TIC deve demonstrar que:

[...] o futuro da educação está na autoeducação, e o papel do professor do futuro seria o de apresentar questões que instigam a curiosidade das crianças, principalmente crianças com menos de 13 anos, mais abertas ao conhecimento e menos ligadas a questões como classes sociais. A reação de crianças abaixo dos treze anos é exatamente igual em qualquer lugar do mundo, afirma o pesquisador. $\mathrm{O}$ emprego dos professores não seria ameaçado. Seria diferente [...]

Seguindo a concepção do autor em relação à tecnologia educacional,

Penso a tecnologia como meios e recursos poderosos, que podem certamente induzir, como já o fazem na escola e em outros 
ambientes frequentados por crianças, adolescentes e jovens, como nos games ou nas redes sociais [...]. Oferecer acesso a computadores, dispositivos móveis e redes é indispensável para a educação, não há dúvida quanto a isso, no entanto, a orientação, o intercâmbio, a reflexão aprofundada e até mesmo o ritmo compassado e diferente dos mestres permanecem como um quesito fundamental (MITRA, 2013, p.1).

De acordo com Takahashi (2000), alguns desafios são constatados com o intuito de destacar a estrutura formal do processo ensino-aprendizagem:

- Alfabetização digital: precisa ser promovida em todos os níveis de ensino, do fundamental ao superior, por meio da renovação curricular para todas as áreas de especialização, de cursos complementares e de extensão, na educação de jovens e adultos, conforme a LDB e Bases da Educação Nacional de 1996.

- Geração de novos conhecimentos: relacionada à formação em nível de pós-graduação. Viabiliza-se, ainda, pela formação profissional em nível de graduação em áreas diretamente relacionadas com tecnologias de informação e comunicação e sua aplicação.

- Aplicação de tecnologias de informação e comunicação: pode ser objeto de formação desde o nível médio, sobretudo no âmbito de cursos técnicos. Direciona-se por ser o foco central de cursos de graduação que tratam de tecnologias de informação e comunicação. Geralmente é uma das preocupações dos cursos de pós-graduação em tecnologias de informação e comunicação e áreas correlatas, especialmente quando a aplicação de conhecimentos que se refere à produção ou ao aperfeiçoamento de bens e serviços na própria área, o que exige o domínio dos fundamentos conceituais básicos associados aos níveis mais elevados de ensino.

- Aplicação de tecnologias de informação e comunicação em quaisquer outras áreas: outras áreas, como saúde, transportes, biologia, também inserem demandas das TIC para explorar a geração de conhecimento. A Figura 5 demonstra essa relação:

Figura 4- Recursos humanos e a as TIC 


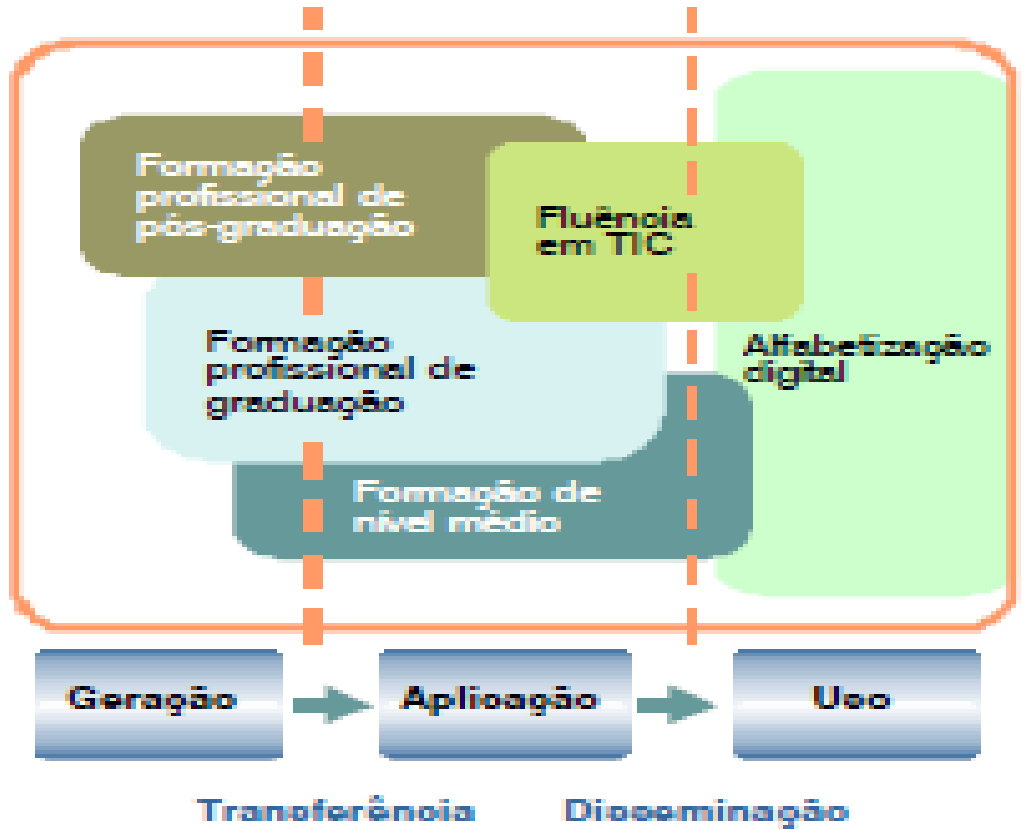

Fonte: Socinfo (2000)

Normalmente, vê-se, nas mídias, o quanto os jovens estão familiarizados com a tecnologia e têm facilidade em seu manuseio. Veem e Vrakking (2009) denominaram jovens desta época de "geração Homo zappiens, que cresceram usando múltiplos recursos tecnológicos desde a infância". Para esses autores, "a geração Homo zappiens é digital, e 
a escola ainda permanece analógica". Idealizando essa afirmação, Mello e Vicária (2008, p.1) indagam:

Nativos digitais e imigrantes digitais, em que faz uma divisão entre aqueles que vêem o computador como novidade e os que não imaginam a vida antes dele, (...) sendo que os nativos digitais têm contato com a tecnologia logo após o nascimento.

Essa ideia vivenciada na sociedade contemporânea tem resultados tanto nas escolas de Educação Básica, Fundamental e de Nível Médio, quanto nas Instituições de Ensino Superior (IES), pois tratam dessa implicação como o novo perfil dos estudantes e dos acadêmicos no mundo (JAQUES RAMOS; FARIA, 2011).

De fato, o advento da Internet favoreceu o desenvolvimento de uma cultura de uso das mídias e, por conseguinte, de uma configuração social pautada num modelo digital de pensar, criar, produzir, comunicar, aprender, enfim, viver. Isso já permite pensar que a atualidade é pautada pela comunicação e pelo gerenciamento da informação e que isso se estabelece de forma totalmente diferenciada daquela dos tempos iniciais da Internet, na década de 90 (noventa), e da utilização dos computadores pessoais até a mesma época.

Além de inserir as TIC nas escolas, é necessária sua integração com a cultura digital, para oportunizar a todos que nela atuam, a participação na cibercultura, que é constituída como o "conjunto de técnicas (materiais e intelectuais), de práticas, de atitudes, de modos de pensamento e de valores" (LÉVY, 2000, p. 17). Isso deve ocorrer por meio da exploração das funcionalidades e serviços oferecidos pelas TIC, em especial pela Internet, como: a comunicação todos-todos a qualquer momento e de qualquer lugar em que se tenha conexão disponível; os distintos caminhos de navegação por meio de nós e ligações que compõem as redes hipermidiáticas, a autoria; a expressão e publicação de ideias que incorporam diferentes linguagens e o desenvolvimento de produções em coautoria.

Para Neves (2009, p. 18), o professor pode promover uma pedagogia de autoria e coautoria em que,

A convergência de mídias, inclusive a que já se encontra nos novos celulares e smartphones, adiciona elementos que revolucionam ainda mais a produção, a distribuição de conteúdos educacionais, a comunicação e a interatividade. Com o uso intencional de todas as tecnologias disponíveis, o professor pode promover uma pedagogia de autoria e coautoria, ancorada em um ambiente educacional tecnológica e pedagogicamente rico, favorecendo a adoção de atitudes autônomas, criativas, 
colaborativas e éticas, tão necessárias à vida em um mundo complexo, em contínua e acelerada evolução.

Ainda para Neves (2009), o professor, na atualidade, assume seu papel em sala de aula, principalmente quando decide usufruir dos recuros demandados pelas TIC. Nesse sentido, pode-se identificar que:

- O professor deve ser motivador: muitas vezes, o professor em sala de aula não utiliza uma TIC, pois acredita que os estudantes já as dominam de forma facilitada. Nesses casos, em virtude desse conhecimento projetado, cabe ao professor permitir que eles façam uso das TIC para beneficiar-se em função do conteúdo programático apresentado, como, por exemplo: se educandos têm dificuldades na escrita, por que não usar um editor de textos para realizar um ditado?

- O professor deve ser um líder: o professor deve conhecer a TIC inserida para transmitir o conhecimento de um determinado conteúdo. Ele deve agir estrategicamente e buscar junto aos estudantes soluções colaborativas e que permitam a participação deles. É necessário lembrar que ser um líder também requer ser aprendiz.

- O professor deve planejar: o docente deve conhecer seus conteúdos programáticos e planejar o uso das TIC em relação a eles. De nada adianta utilizar uma TIC sem o planejamento adequado, pois a intenção de uma ferramenta como esta é auxiliar o professor no processo ensinoaprendizagem e não torná-la um recurso isolado para ajudar o docente, quando este não possui suas aulas previamente preparadas.

- O professor deve gerenciar o tempo: muitos usuários acreditaram que as TIC poderiam realizar a demissão de diversos trabalhadores. Pode-se dizer, nesse sentido, que essa informação é um conceito intangível e inadequado. O professor deve conhecer o momento certo de trazer para o ambiente escolar a relação entre a teoria e a prática, e nada mais concreto do que gerenciar o fator tempo para essa finalidade. Impor a condição de que a TIC é uma forma de aprendizado rápida, é um conceito errôneo, pois mesmo com a inserção da tecnologia, o tempo de aprendizado é relevante para que o docente ensine e o aluno aprenda o conteúdo.

- O professor deve harmonizar os conteúdos e as tecnologias: em um ambiente, o docente deve ser o responsável pela escolha das tecnologias com que irá trabalhar no processo ensino-aprendizagem. Para isso, é preciso que o professor conheça as TIC disponíveis na escola em que se insere e, dessa forma, saiba utilizá-las de acordo com os conteúdos ministrados por ele em sala de aula.

- O professor deve fazer a avaliação: o propósito da avaliação com o uso da TIC deixa de ser aquele que está apenas no papel. Com o uso da tecnologia, os processos de interação e a construção do conhecimento por parte do aluno permitem que esse construa suas habilidades e demonstre competências de acordo com a evolução do aprendizado. 
Na mesma linha de pensamento de Almeida (2004) e Jaques Ramos e Faria (2011) comentam que o uso das TIC exige planejamento, acompanhamento e avaliação da tecnologia selecionada, a fim de contextualizá-la ao tipo de aluno, aos objetivos da disciplina, ao modelo teórico-referencial educacional adotado. Complementando esse segmento, as autoras descrevem,

[... a tecnologia educacional deve auxiliar o aluno na sua aprendizagem e não dificultar como também deve propiciar melhores condições de ensino e não assustar o professor, já tão sobrecarregado de atividades educacionais. No entanto, sabemos que o início de uma nova atividade é sempre difícil, por isso deve ser implantada aos poucos, passo a passo, para ter sucesso. Enfatiza-se que, [...] estes docentes, por sua vez, aplicando adequadamente esta Tecnologia educacional e digital no cenário contemporâneo, sensibilizarão e ensinarão seus alunos a aderirem e a se movimentarem bem neste contexto tecnológico. Desta forma, faremos não só a inclusão digital desta parcela da população que encontrará alunos nativos digitais em suas futuras aulas, como tornar-se-ão usuários conscientes da importância da aplicação da tecnologia na educação [...] (JAQUES RAMOS; FARIA, 2011, p.16-17)

Silva (2000, p.360) demonstra que educar com as TIC exige mudanças na gestão da escola e das redes de ensino:

[...] num ambiente de comunicação e conhecimento baseado na liberdade, na pluralidade e na cooperação. Algo diferente da socialização cultivada pela escola-fábrica baseada no falar-ditar do mestre e nas lições-padrão que deveriam formar o ser social $[\ldots]$.

A ideia de Neves (2009) reforça que educar com TIC não se restringe a investimentos em infraestrutura física e tecnológica. Implantar essa nova arquitetura pedagógica exige, ainda, um conjunto amplo e articulado de ações que contemplam investimentos, primeiramente em profissionais das escolas e dos sistemas de ensino para domínio de linguagens e tecnologias; em oficinas e discussões organizadas para estabelecer princípios e políticas de trabalho, adequação dos projetos pedagógicos e avaliação; em revisão de currículo, desenho e estratégias tecnológicas dos cursos e, por fim, em sistemas de gestão e logística informatizada, entre outros.

\section{Conclusão}


Ao se planejar a Escola, a escolha da tecnologia apropriada pode criar oportunidade para melhorar a qualidade das atividades de sala de aula, pois um plano de tecnologia está relacionado fundamentalmente a "pessoas e tecnologia, e prevê acões visando à aprendizagem dos alunos, mas para isso é essencial que preveja acões de formação e desenvolvimento dos professores" (ALMEIDA, 2004).

Não somente as tecnologias devem ser exploradas em sua funcionalidade, mas a preparação dos professores é ponto decisivo no que tange à propriedade do ensino, pois os educandos estão quase sempre prontos para a utilização das tecnologias, enquanto a maioria dos professores não. As aulas dadas tradicionalmente geram e abalam o conhecimento "inquestionável" dos docentes: o "grande desafio consiste em integrar os professores com a cultura tecnológica para o processo de ensino e aprendizagem" (BARROS, 2007, p 106)

Ponte (2000, p. 2) destaca que o processo de apropriação das TIC, além de ser necessariamente longo, envolve duas facetas que não se podem confundir: a tecnológica e a pedagógica:

\begin{abstract}
Alguns olham-nas com desconfiança, procurando adiar o máximo possível o momento do encontro indesejado. Outros usam-nas na sua vida diária, mas não sabem muito bem como as integrar na sua prática profissional. Outros, ainda, procuram usá-las nas suas aulas sem, contudo, alterar as suas práticas. Uma minoria entusiasta desbrava caminho, explorando incessantemente novos produtos e ideias, porém defronta-se com muitas dificuldades como também perplexidades (PONTE, 2000, p. 2).
\end{abstract}

Como se nota, o docente é um importante elemento nesse novo processo de interação da tecnologia com a Educação. Assim, é necessário que os professores "saibam incorporar e utilizar as novas tecnologias no processo de aprendizagem, exigindo-se uma nova configuração do processo didático-metodológico tradicionalmente usado em nossas escolas" (MERCADO, 1999, p. 14).

Considerando recursos, plataformas e ferramentas utilizadas atualmente, vislumbram-se novos desafios. É necessário utilizar novas linguagens em favor dessas novas oportunidades de ensino-aprendizagem. Várias especialidades precisarão ser integradas para que o resultado seja consistente, ofereça desafios e possibilite saltos de aprendizagem (AZEREDO RIOS, 2013). É possível, portanto, uma análise do desafio relacionado ao uso de tecnologia nas escolas: a resistência do professor em propor mudanças. 
Nesse sentido, percebe-se que o conhecimento disponibilizado pela Internet faz com que o docente seja subtraído da posição de detentor único do conhecimento. Para tanto, esse professor precisa lidar com uma nova realidade, que pressupõe aprender novamente, desde conhecer e exercitar práticas usando os novos recursos tecnológicos até estimular a participação do aluno de outras formas, bem como reorganizar o ambiente na sala de aula para permitir tal interação.

No que se refere ao processo ensino-aprendizagem, é preciso destacar o que o uso das metodologias tecnológicas em sala de aula leva o educando a aprimorar a sua capacidade de aprender e de trabalhar de forma colaborativa, solidária, centrada na rapidez e na diversidade qualitativa das conexões e das trocas, aspectos essenciais para a boa convivência na atual sociedade modernizada (Bittencourt et al., 2004)

Como afirma Demo (2009, p.19), sobre a postura do professor no atual contexto educacional:

Elemento humano responsável pelo ambiente de aprendizagem, origem das interações e inter-relações entre os indivíduos participantes do ambiente educacional, testemunhas de outras mudanças e experiências, condicionado por uma educação do passado e marcado por ela (...) o professor deverá firmar um novo compromisso com a pesquisa, com a elaboração própria, com o desenvolvimento da crítica e da criatividade, superando a cópia, o mero ensino e a mera aprendizagem, uma postura que deverá manter quando estiver trabalhando num ambiente informatizado.

Assim, as inovações advindas das tecnologias de informação e comunicação tornam-se parte de um sistema de relações, dificultando a demarcação do que é tecnológico e do que é social.

\section{Referências}

ALAVA, S. Ciberespaço e formações abertas: rumo a novas práticas educacionais?. Porto Alegre: Artmed, 2002, p. 13-21.

ALMEIDA, M. E. B. Tecnologia de informação e comunicação na escola: aprendizagem e produção da escrita. Série "Tecnologia e Currículo" - Programa Salto para o Futuro, novembro, 2001.

O eu e o outro no grupo. Publicação interna em documentos disponibilizados em cursos promovidos pelo Programa de Pós-Graduação em Educação: Currículo da PUC-SP, São Paulo, 2004. 
AZEREDO RIOS, T. O valor do não saber. Revista Gestão Escolar. São Paulo: Fundação Victor Civita, abril/maio, 2013.

BARROS, D. M. V. Formação continuada para docentes do Ensino Superior: O virtual como espaço educativo. Revista Diálogo Educacional. Curitiba, v. 7, n. 20, p. 103- 122, jan./abr. 2007.

BIZELLI, J. L. Inovação: limites e possibilidades para aprender na era do conhecimento. São Paulo: Ed. da UNESP: Cultura Acadêmica, 2013. v.1.

BITTENCOURT, C. S.; GRASSI, D.; ARUSIEVICZ, F.; TONIDANDEL, I. Aprendizagem colaborativa por computador. Novas Tecnologias na Educação, v. 2 n. 1, mar/2004, p. 1-5. Disponível em: <http://www.cinted. ufrgs.br/renote/mar2004/artigos/01-aprendizagem_colaborativa.pdf >. Acesso em 6 abr. 2014.

BORGES, M. K. Educação e Cibercultura: perspectivas para a emergência de novos paradigmas educacionais. In VALLEJO, A.P.; ZWIEREWICZ, M. (Org.). Sociedade da informação, educação digital e inclusão. p. 53-86. Florianopolis: Insular, 2007.

BRUNNER, J. J. Formación Docente y las Tecnologías de Información e Comunicación. (2010) Disponível em http://mt.educarchile.cl/mt/jjbrunner/archives/orealc_prof\%26tic.pdf. Acessado em: 25 mar. 2014.

BULKELEY, W. M. Hard Lessons. The Wall Street Journal, Technology, November 17, p.1-36, 1997.

CARNEIRO, R. Informática na educação: representações sociais do cotidiano. 2. ed. São Paulo: Cortez, 2002.

CASTELLS, M. A Sociedade em rede - A era da informação: economia, sociedade e cultura. vol I. São Paulo: Paz e Terra, 1999.

CASTRO, M. L. D. de, et al. Mídias e processos de significados. UNISINOS. Rio Grande do Sul, 2000.

CHAHIN, A.; CUNHA, M. A.; KNIGHT, P. T.; PINTO, S. E-gov.br: a próxima revolução brasileira. São Paulo: Prentice Hall, 2004.

CRUZ, D.; MORAES, M. Tecnologias de Comunicação e Informação para o Ensino a Distância na Integração Universidade/Empresa. 2002. Disponível em: <http://www.intelecto.net/ead_textos/tecno1.htm>. Acesso em: 23 jun. 2014.

DEMO, P. Desafios Modernos da Educação. Petrópolis, RJ: Vozes, 2009.

EVANS, T. Uma revisão da educação superior a distância: uma perspectiva Australiana. In CONGRESSO DE ENSINO SUPERIOR A DISTÂNCIA APRESENTAÇÃO, I, 2002. Petrópolis. Anais. Petrópolis: ESud, 2002. 
FREIRE, P.; SHOR, I. Dialogues on Transforming Education. Londres: MACMILLAN, 1986.

JAQUES RAMOS, M.B.; FARIA, E.T. Aprender e ensinar: diferentes olhares e práticas. Porto Alegre: PUCRS, 2011, p.299.

JOHNSON, S. Cultura da Interface: como o computador transforma nossa maneira de criar e comunicar. Rio de Janeiro: Jorge Zahar, 2001.

KENSKI, V. M. Educação e Tecnologias: o novo ritmo da informação. Campinas, SP: Papirus, 2007.

LÉVY, P. As tecnologias da inteligência: o futuro do pensamento na era da Informática, 34. ed. 1998.

Cibercultura. São Paulo: Editora 34, 2000.

MERCADO, L. P. L. Formação continuada de professores e novas tecnologias. Maceió. EDUFAL, 1999.

MELLO, K.; VICÁRIA, L. Os filhos da era digital: Como o uso do computador está transformando a cabeça das crianças - e como protegê-las das ameaças da Internet. Revista Época, n. 486 de 12/06/08. Disponível em: <http://revistaepoca.globo.com/Revista/Epoca/0,EDG78998-6014-486,00OS+FILHOS+DA+ERA+DIGITAL.html> Acesso em: 20 nov. 2014.

MITRA, S. A educação do futuro. Disponível em <http://pensarecausar.wordpress.com/2013/11/06/sugata-mitra-e-a-educacao-do-futuro> 2013. Acesso em: 24 out. 2014.

- Um professor pode ser substituído por uma máquina. Disponível em <http://revistaepoca.globo.com/Ciencia-e-tecnologia/noticia/2012/02/sugata-mitra-umprofessor-pode-ser-substituido-por-uma-maquina.html> (2012). Acesso em: 23 out. 2014.

MORAES, M. C. Subsídios para Fundamentação do Programa Nacional de Informática na Educação. Secretaria de Educação a Distância, Ministério de Educação e Cultura, jan.1997.

MORAN, J. M. Desafios da Internet para o Professor. Disponível em: http://www.eca.usp.br/eca/prof/moran/desafio.htm (1998). Acesso em: 10 out. 2014.

NEITZEL, L. C. Novas Tecnologias e Práticas Docentes: o hipertexto no processo de construção do conhecimento (uma experiência vivenciada na rede pública estadual de Santa Catarina). 2001. Dissertação (Mestrado em Mídia e Conhecimento), Universidade Federal de Santa Catarina, Florianópolis.

NETO, F. J. S. L. Tecnologia educacional. Instituto Nacional de Estudos e Pesquisas Educacionais (INEP). Brasília, ano 1, n.7, jun. 1982. 46 p. 
NEVES, C. M. C. Educar com TICs: o caminho entre a excepcionalidade e a invisibildiade. Botelim Técnico Senac. Rio de Janeiro, v. 35, n. 3, set./dez. 2009.

NOGUEIRA, V. S. O educador frente às novas tecnologias. 2010. Disponível em: $<$ http://www.educador.brasilescola.com/trabalho-docente/o-educador-frente-as-novastecnologias.htm> Acesso em: 22 nov. 2012.

OROZCO, G. G. Comunicação, educação e novas tecnologias: tríade do século XXI. Comunicação e Educação, São Paulo, n. 23, p. 57-70, jan./abr. 2002.

PIMENTA, S. G. (Org.). Saberes pedagógicos e atividade docente. São Paulo: Cortez, 1999.

PRETTO, N. de L. (org.). Globalização \& organização: mercado de trabalho, tecnologias de comunicação, educação a distância e sociedade planetária. Ijuí: Ed. Unijuí, 1999.

PONTE, J. P. da. Tecnologias de informação e comunicação na formação de professores: Que desafios? Revista Ibero-Americana de Educación. OEI. n. 24, septiembre/diciembre, 2000. Disponível em http://www.oei.es/revista.htm. Acesso em: 10 set. 2014.

QUARTIERO, E. M. As tecnologias da informação e comunicação e a educação. Revista Brasileira de Informática na Educação - n.4 - 1999.

RIBAS, C. O profissional da informação: rumos e desafios para uma sociedade inclusiva. Informação \& Sociedade, João Pessoa, v. 17, n. 3, set./dez. 2007, p47-57.

SANCHO, J. M.; HERNÁNDEZ, F. (Org.). Tecnologias para transformar a Educação. Porto Alegre: Artmed, 2006.

SANTOS, M. et al. Ensinar e aprender com a metodologia Syllabus, Revista de Educação, Brasília, n. 150, ano 38, jan./jun. 2010, p.21-27.

SILVA, M. A. Sala de aula interativa. 2. ed. Rio de Janeiro: Quartet:, 2000. p. 360.

SILVA, H. P. da. Governo eletrônico e informação utilitária: uma relação necessária para uma efetiva inclusão digital. 2007. Disponível em: <http://www.escoladegoverno.pr.gov.br/arquivos/File/Material \%20CONSAD/paineis III_congresso_consad/painel_5/governo_eletronico_a_busca_por_um_governo_mais_tr ansparente e democratico.pdf $>$. Acesso em 20 fev. 2014.

SIMÕES, V. A. P. Utilização de novas tecnologias educacionais nas escolas da rede estadual da cidade de Umuarama - PR. Dissertação de mestrado em educação. UFU, 2002.

SOUZA, M. A. T. de. Novas tecnologias: novos rumos para a educação, 2007. Disponível em:<http://www.artigos.com/artigos/exatas/computacao/novas-tecnologias2531/artigo/> Acesso em: 27 nov. 2012. 
TAKAHASHI, T. Sociedade da informação no Brasil: livro verde. Brasília: Ministério da Ciência e Tecnologia, 2000.

THOMPSON, J. B. Ideologia e cultura moderna: teoria social crítica na era dos meios de comunicação de massa. Petrópolis: Vozes, 1998.

VALENTE, J. A. Por Quê o Computador na Educação. In: VALENTE, J. A (Org.). Computadores e Conhecimento: repensando a educação (p. 24-44). Campinas, SP: Gráfica da UNICAMP, 1993.

VARGAS, M. (Org.) História da técnica e da tecnologia no Brasil. São Paulo: Ed. Unesp: Centro Estadual de Educação Tecnológica Paula Souza, 1994.

VEEM, W.; VRAKKING, B. Homo Zappiens: Educando na era digital. Porto Alegre: Artmed, 2009. 139p.

VIEIRA, A. T.; ALMEIDA, M. E. B. de.; ALONSO, M. (org.). Gestão Educacional e Tecnológica. São Paulo: Avercamp, 2003.

VIEIRA PINTO, A. O conceito de tecnologia. Rio de Janeiro: Contraponto, 2005. Vol. I. 